\title{
Dynamic Thermogravimetric Analysis of Recycled Carbon Fiber Composites: Mini Review
}

\author{
Seyed Hossein Mamanpush ${ }^{1,2 *}$, Reyhaneh Tavousi Tabatabaei ${ }^{2}$ and Bahareh Tavousi Tabatabaei ${ }^{2}$ \\ ${ }^{1}$ Composite Materials and Engineering Center, Washington State University, Pullman, WA, 99163, USA
}

${ }^{2}$ Department of Engineering, Islamic Azad University, Khomeyni Shahr Branch, Isfahan, Iran

*Corresponding author: Seyed Hossein Mamanpush, Composite Materials and Engineering Center, Pullman, WA, 99163, USA.

\begin{abstract}
Thermogravimetric analysis (TGA) is one of the most popular analysis techniques to study the decomposition process of polymeric materials in controlled atmospheres at various temperatures. In this review, dynamic TGA was carried out to determine the thermal stability of the recycled epoxy-based and vinyl ester-based carbon fiber composite (CFC). The specimens were heated from ambient to $800^{\circ} \mathrm{C}$ under nitrogen and air at different heating rates. Results indicates that different heating rates has no significant influence on the degradation of the epoxy-based CFC.
\end{abstract}

Keywords: Recycling; TGA; Carbon fiber composite

\section{Introduction}

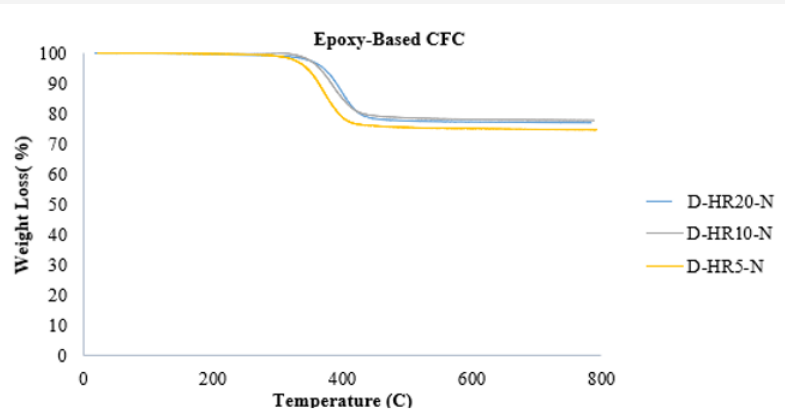

Figure 1 : Dynamic TGA curve recorded in nitrogen at different heating rates. (Note: HR indicates heating rates).

TGA can be used to evaluate the thermal stability of a material. In a desired temperature range [1,2], if a species is thermally stable, there will be no observed mass change [3]. Negligible mass loss corresponds to little or no slope in the TGA trace $[4,5]$. The dynamic TGA results of recycled epoxy-based CFC materials at different heating rates indicate that there is no significant difference among the thermal degradation profiles (Figures 1 \& 2). For the heating rate of $5^{\circ} \mathrm{C} \mathrm{m}-1$ degradation events started around $300^{\circ} \mathrm{C}$ and at the heating of $10^{\circ} \mathrm{C} \mathrm{m}^{-1}$ and $20^{\circ} \mathrm{C} \mathrm{m}^{-1}$ it started around $330^{\circ} \mathrm{C}[6,7]$. At $800^{\circ} \mathrm{C}$ the TGA results of recycled epoxy-based CFC material shows the residue around $75 \%$ that remained, this can be assigned to the carbon fiber content of the sample [8-10].

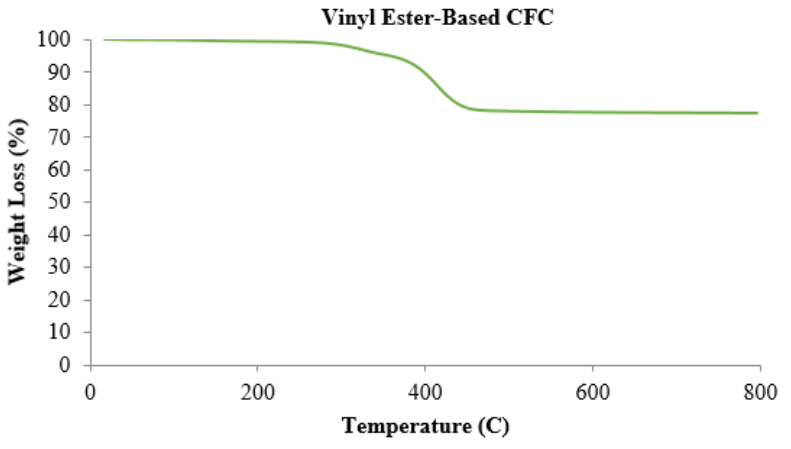

Figure 2: Dynamic TGA curve recorded in nitrogen at heating rate

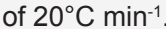

Based on this fact that heating rate has no significant influence on the TGA results of recycled CFCs [11], for recycled vinyl esterbased CFCs we just consider the $20^{\circ} \mathrm{C}$ min- 1 heating rete (Figures 3 \& 4). For vinyl ester-based CFC material degradation event occur between $300^{\circ} \mathrm{C}$ to $456^{\circ} \mathrm{C}$. At $800^{\circ} \mathrm{C}$ the TGA results of recycled 
vinyl ester-based $\mathrm{CFC}$ material shows the residue around $77 \%$ that remained, this can be assigned to the carbon fiber content of the sample [12]. Comparing the TGA results of recycled epoxy-based CFC and vinyl ester-based CFC shows that there is no significant difference between degradation behavior of them. The TGA results of recycled CFCs in air show that recycled vinyl ester-based CFC have better thermal stability comparing to epoxy-based CFCs. At $800^{\circ} \mathrm{C}$ the TGA results of recycled vinyl ester-based CFC material shows the residue around 59\% that remained, and results of recycled epoxy-based CFC material shows the residue around $0 \%$, it shows the significant thermal stability of vinyl ester-based CFC in air.

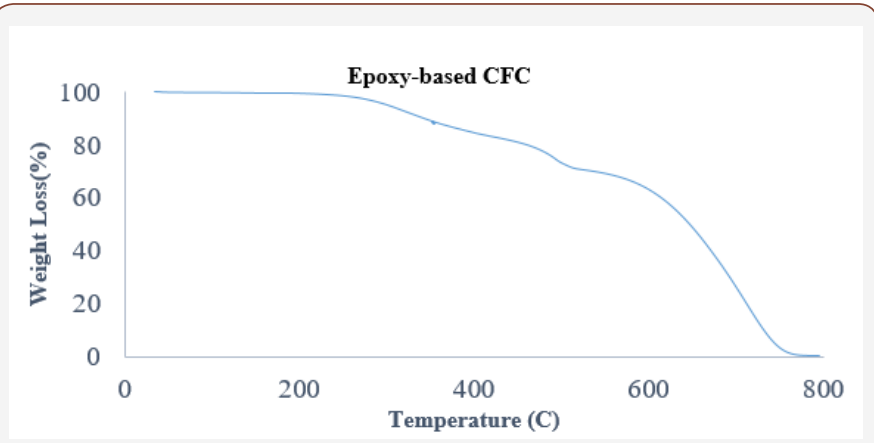

Figure 3: Dynamic TGA curve recorded in Air at heating rate of $20^{\circ} \mathrm{C}$ min $^{-1}$.

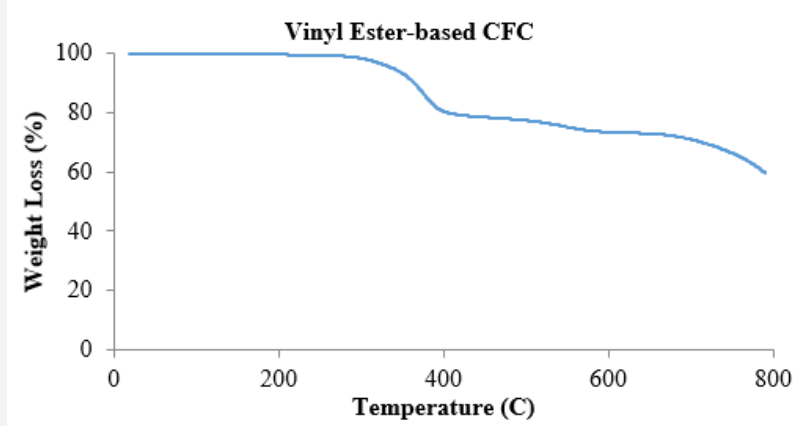

Figure 4: Dynamic TGA curve recorded in Air at heating rate of $20^{\circ} \mathrm{C} \mathrm{min}^{-1}$.

\section{Conclusion}

Recycled CFCs are a viable material for making second generation composites. The obtained results from dynamic TGA of recycled carbon fiber composite materials demonstrate that recycled CFCs have superior thermal stability. Results indicates that different heating rates has no significant influence on the degradation of the epoxy-based CFC.

\section{Acknowledgement}

None.

\section{Conflict of Interest}

No Conflict of Interest.

\section{References}

1. Hui Li, Karl Englund (2016) Recycling of carbon fiber-reinforced thermoplastic composite wastes from the aerospace industry. Journal of Composite Materials 51(9): 1265-1273.

2. Mamanpush $H$, Golestanian $H$ (2014) Investigating the effects of carbon nanotube orientation on the macroscopic stiffness of nanocomposites. Int J Curr Life Sci 4(4): 1168-1174.

3. Mamanpush H, Golestanian H (2014) Evaluation of effective material properties of randomly distributed carbon nanotube composites considering interface effect. Indian J Sci Res 2(1): 132-142.

4. Thostenson ET, Karandikar PG, Chou TW (2005) Fabrication and characterization of reaction bonded silicon carbide/carbon nanotube composites. J Phys D Appl Phys 38(21): 3962-3965.

5. Song YS, Youn JR (2006) Modeling of effective elastic properties for polymer-based carbon nanotube composites. Polymer 47(5): 17411748 .

6. Mamanpush H, Golestanian H (2014) Effects of carbon nanotube dispersion on the mechanical properties of nanocomposites considering interface effect. International Journal of Current Research 4(8): 43664373.

7. Seyed Hossein Mamanpush, Hui Li, Karl Englund, Azadeh Tavousi Tabatabaei (2018) Recycled wind turbine blades as a feedstock for second generation composites. Waste Management 76: 708-714.

8. Seyed Hossein Mamanpush, Azadeh Tavousi Tabatabaei, Hui Li, Karl Englund (2018) Data on the mechanical properties of recycled wind turbine blade composites. Data in Brief 19: 230-235.

9. Seyed Hossein Mamanpush, Hui Li, Karl Englund, Azadeh Tavousi Tabatabaei (2018) Dataset demonstrating physical properties of recycled wind turbine blade composites. Data in Brief 20: 658-661.

10. Seyed Hossein Mamanpush, Azadeh Tavousi Tabatabaei (2018) Innovative Method in Recycling Wind Turbine Blades: Mini Review. Evolutions Mech Eng 1(1): 1-2.

11. Seyed HM, Zohre MG, Hossein G (2018) Numerical Modeling of Nano Bundle and Nano Rope-Reinforced Polymer Mechanical Properties. Evolutions Mech Eng 1(4): 1-9.

12. Azadeh Tavousi Tabatabaei, Seyed Hossein Mamanpush, Bahareh Tavousi Tabatabaei (2018) Effects of Carbon Nanotube Dispersion on the Material Properties of Polymer Matrix Composites. Evolutions Mech Eng 1(3). 